\title{
Reservoir differences and formation mechanisms in the Ke-Bai overthrust belt, northwestern margin of the Junggar Basin, China
}

\author{
Zhu Xiaomin ${ }^{1,2 *}$, Zhu Shifa ${ }^{1,2}$, Xian Benzhong ${ }^{1,2}$, Chen Shuping1, \\ Kuang Lichun ${ }^{3}$, Xue Xinke ${ }^{3}$, Xue Jingjing ${ }^{3}$ and You Xincai ${ }^{3}$ \\ ${ }^{1}$ State Key Laboratory of Petroleum Resources and Prospecting, China University of Petroleum, Beijing 102249, China \\ ${ }^{2}$ Faculty of Geoscience, China University of Petroleum, Beijing 102249, China \\ ${ }^{3}$ Research Institute of Petroleum Exploration and Development, Xinjiang Oilfield Company, CNPC, Karamay, Xinjiang \\ 834000 , China
}

(C) China University of Petroleum (Beijing) and Springer-Verlag Berlin Heidelberg 2010

\begin{abstract}
There are some differences in reservoir quality of clastic rock between the hanging wall and the foot wall of the Ke-Bai overthrust belt, northwestern margin of the Junggar Basin, western China, which affect the efficient petroleum exploration in this highly mature exploration area. Based on a large number of thin-sections, cast thin-sections, and physical property analysis of cores, we systematically discuss the Permian-Jurassic reservoir differences between the hanging wall and the foot wall of the KeBai overthrust fault from the aspects of structural evolution, time-space distribution of the depositional system, diagenesis characteristics, and reservoir quality and analyzed the reasons for the differences in reservoir properties. The overthrusting of the Ke-Bai fault directly results in different burial histories, diagenesis evolution, and porosity evolution between the hanging wall and the foot wall. The differences of reservoir characteristics are mainly embodied in buried depth, grain size, sedimentary facies, diagenetic stage, and reservoir quality. The analysis results showed that burial history and depositional characteristics controlled by overthrusting are direct influencing factors of reservoir differences. Because of shallow burial depth of the hanging wall, the reservoir compaction is weak and primary pores are preserved well. The porosity of reservoir on the hanging wall is generally $10 \%-25 \%$. The strata on the foot wall are deeply buried, and there are mainly mixed pores with the average porosity of $5 \%-20 \%$. The favorable reservoir on the foot wall is generally developed near faults or in the channel sand bodies, which are usually dissolution development areas.
\end{abstract}

Key words: Junggar Basin, overthrust belt, reservoir differences, formation mechanism

\section{Introduction}

The Karamay Oilfield, which is located in the overthrust belt at the northwestern margin of the Junggar Basin, is the first and largest oilfield discovered in the Midwest of China. The Ke-Bai overthrust belt formed in the middlelate Hercynian is compression-nappe fracture. It formed in the Indo-Chinese epoch and the napping ended in the middle Yanshan Movement. The early faults have a long active stage, and are characterized by overriding and contemporaneous faulting, which provide favorable conditions for hydrocarbon generation, accumulation, capping, and migration, so a broad hydrocarbon enrichment zone in northwestern margin is formed (Tan et al, 2008; Kuang et al, 2008; Lu et al, 2008).

*Corresponding author. email: xmzhu@cup.edu.cn Received September 4, 2009
Long-term activities of overthrust fault result directly in different buried depths of strata, lithofacies, lithology, and reservoir properties between the hanging wall and the foot wall. Previous studies showed that burial history was a major controlling factor of reservoir quality (Payne, 1987; Harris, 1989). Bloch et al (1990) studied the effect of burial history on porosity of sandstones, and thought that although two sets of Cretaceous sandstones were buried at nearly same depths and had similar composition and texture, their porosities were significantly different because of different burial histories. Shou et al (2003) analyzed the relationship between lateral structure compression and compaction in Cretaceous of the southwest depression in the Tarim Basin, and demonstrated that the deformation was weak and the physical properties of reservoir beds were quite good in the front zone of the thrust nappe belt in the front of the Kunlun Mountains. However, in the middle zone of the thrust nappe belt, the deformation was strong, a lot of shear fractures developed, and the reservoir 
porosity was low. In this paper, on the basis of previous studies and the evolution of the overthrust fault, we analyzed the effect of different burial histories of the Permian-Jurassic strata (main oil-producing formation) between the hanging wall and the foot wall of the overthrust fault in the Karamay Oilfield on lithofacies, lithology, and differences of reservoir properties, and studied the formation mechanism of reservoir differences, which provide a scientific geological foundation for hydrocarbon exploration in the northwestern margin of the Junggar Basin.

\section{Formation and evolution of the overthrust fault}

The late Paleozoic - early Mesozoic overthrust fault in the northwestern margin is the result of large-scale thrust and nappe tectonics. The initial collision began in the earlymiddle Carboniferous, intensified in the late Carboniferous to early Permian, and the nappe was formed. In the late Permian, extrusion and thrusting reached its maximum, and the nappe overrode the sediments in the foreland depression.
The thrusting was syndepositional and a lot of alluvial fans deposited in the frontal zone. The thrusting weakened in the Triassic - middle Jurassic and the nappe was buried after the middle Jurassic. The giant nappe structure extends from Chepaizi area in the south to Xiazijie area in the north via Karamay with a length of $250 \mathrm{~km}$ and width of 20-30 $\mathrm{km}$ (Zou et al, 2007). Based on different formation time, activity patterns, and stress conditions, the overthrust belt in the northwestern margin could be divided into three fault zones with different structure deformation and geologic configuration: Hongshanzui-Chepaizi (Hong-Che) fault zone in the south, Karamay-Wuerhe (Ke-Wu) fault zone with compresso-shearing character in the middle and WuerheXiazijie (Wu-Xia) fault zone with thrusting character in the north. The three fault zones are separated by lateral ramp, oblique ramp or cross faults (He et al, 2004). The Ke-Bai overthrust fault studied in this paper is a part of the $\mathrm{Ke}-\mathrm{Wu}$ fault zone in the northwestern margin (Fig. 1).

Starting from Karamay in the west, the Ke-Bai overthrust belt stretches northeast to Baijiantan and Baikouquan areas, with an inverse "S" shape, widening to southwest (Fig. 1).
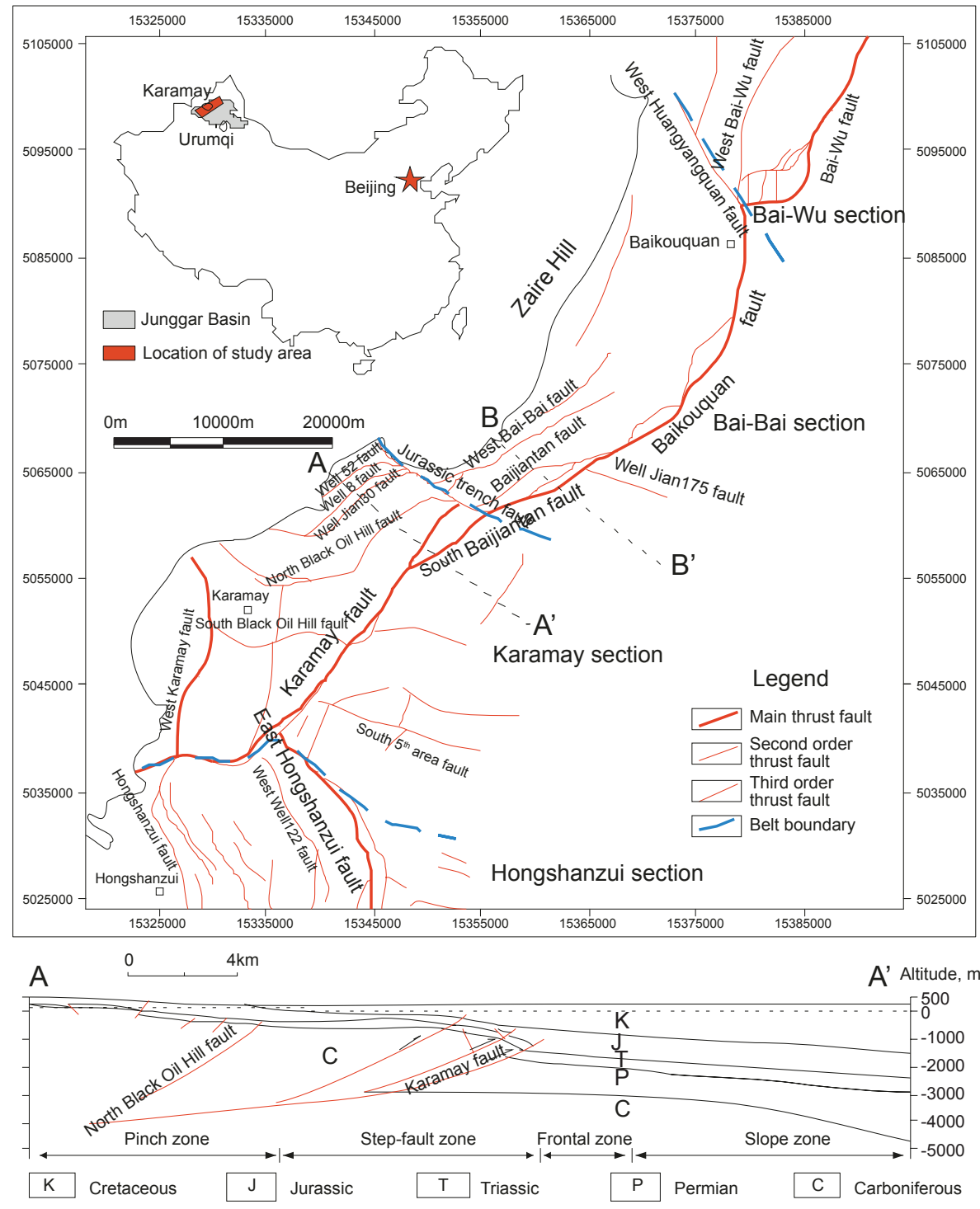

Fig. 1 Fault distribution map and structural profiles of the Ke-Bai area, Junggar Basin 
The study area is divided into two belts by the deep Jurassic trench. The north belt is the centralized area of compressional stress, the fault extends towards the basin in an arc shape and many fault blocks develop in the frontal zone. For large thrusting displacement, the width of the frontal folded zone of the nappe becomes small, only $5 \mathrm{~km}$ across. The thrusting displacement in the south belt is relatively smaller than that in the north belt, so the width of frontal folded zone is larger, more than $20 \mathrm{~km}$.

The Ke-Bai overthrust fault zone is composed of the Baikouquan, South Baijiantan, Karamay and Bai-Wu faults, which are all syndepositional faults (Fig. 1). The Hercynian, Indo-Chinese, and Yanshan movements affected the formation of the fault zone, especially in the Hercynian and Yanshan periods. There are no Permian and middle-upper Carboniferous strata on the hanging wall of the nappe because of the Hercynian movement. The Indo-Chinese movement is expressed near the Baijiantan fault on the hanging wall. The early Yanshan movement has a strong influence on the whole area. Both fracturing and folding are intense, but fracturing is more important.

Affected by the growth fault, the buried depth of PermianJurassic reservoir between the hanging wall and the foot wall is different (Table 1). On the hanging wall, the Permian strata are missing, and in some areas, there are no Triassic and Jurassic strata. While on the foot wall, the strata are completely developed, and the buried depth and thickness of the strata increase towards the slope area.

Table 1 Clastic reservoir differences between the hanging wall and the foot wall of the Ke-Bai overthrust fault

\begin{tabular}{|c|c|c|c|c|c|}
\hline Area & \multicolumn{2}{|c|}{ Hanging wall } & \multicolumn{3}{|c|}{ Foot wall } \\
\hline Strata & Triassic & Jurassic & Permian & Triassic & Jurassic \\
\hline Depth, m & $60-2290$ & $0-1200$ & $1500-4500$ & $1200-3750$ & $1000-2200$ \\
\hline Thickness, $\mathrm{m}$ & $0-600$ & $0-400$ & $800-1600$ & $500-1000$ & $600-1000$ \\
\hline Facies & $\begin{array}{l}\text { alluvial fan, } \\
\text { braided river }\end{array}$ & $\begin{array}{l}\text { braided } \\
\text { river }\end{array}$ & fan delta & $\begin{array}{l}\text { braided river delta, } \\
\text { alluvial fan }\end{array}$ & $\begin{array}{c}\text { (braided river) } \\
\text { delta }\end{array}$ \\
\hline Lithology & $\begin{array}{c}\text { sandy conglomerate, } \\
\text { pebbled sandstone }\end{array}$ & $\begin{array}{c}\text { pebbled } \\
\text { sandstone, } \\
\text { sandstone }\end{array}$ & $\begin{array}{c}\text { sandy } \\
\text { conglomerate, } \\
\text { conglomerate }\end{array}$ & $\begin{array}{l}\text { (pebbled) sandstone, } \\
\text { sandy conglomerate }\end{array}$ & sandstone \\
\hline Diagenetic stage & $\begin{array}{c}\text { from stage } \mathrm{B} \text { of the } \\
\text { early diagenetic phase } \\
\text { to stage } \mathrm{A} \text { of the middle } \\
\text { diagenetic phase }\end{array}$ & $\begin{array}{c}\text { early } \\
\text { diagenetic phase }\end{array}$ & $\begin{array}{c}\text { stage A of } \\
\text { the middle } \\
\text { diagenetic phase }\end{array}$ & $\begin{array}{c}\text { stage A of } \\
\text { the middle } \\
\text { diagenetic phase }\end{array}$ & $\begin{array}{c}\text { from stage } \mathrm{B} \text { of the } \\
\text { early diagenetic phase } \\
\text { to stage } \mathrm{A} \text { of the middle } \\
\text { diagenetic phase }\end{array}$ \\
\hline Porosity, $\%$ & 16.4 & 21.3 & 8.9 & 12.2 & 15.8 \\
\hline $\begin{array}{l}\text { Permeability, } \\
\quad \times 10^{-3} \mu^{2}\end{array}$ & 259 & 554 & 32 & 63 & 88 \\
\hline $\begin{array}{l}\text { Sample } \\
\text { number }\end{array}$ & 6231 & 7963 & 3748 & 8759 & 1138 \\
\hline
\end{tabular}

\section{Lithological differences between the hanging wall and the foot wall controlled by overthrust fault}

The space-time distribution of depositional systems in the Ke-Bai area is controlled by the Zaire Hill orogenic wedge and the Ke-Bai overthrust fault. The formation, distribution, and evolution of alluvial fan, fan delta, and braided river delta facies deposited in the Permian-Jurassic are certainly related to the activity of the growth fault (Lei et al, 2005a; 2005b). For the fracturing unbalance and the movement asymmetry, there is an obvious difference in the burial history between the hanging wall and the foot wall during different periods, which results in different lithofacies and lithology (Table 1): Facies developed on the hanging wall include proximal alluvial fan and braided river sediments, and fan delta, braided river delta deposits occurring in the foot wall.
In the Permian period the basin was characterized by foreland basin facies. The Ke-Bai fault (no segmentation at the moment) was a boundary fault that controlled depositional process. Lots of fans developed on the foot wall along the fault, and the strata were completely eroded on the hanging wall. Sandy conglomerate and alluvial fan and fan delta conglomerates, pyroclastics, and volcanics were all developed in the Permian. In the Jiamuhe Formation of the lower Permian and the upper Wuerhe Formation of the upper Permian, many fan bodies developed. The distribution scope and scale of the fan bodies in the Fengcheng Formation of the lower Permian were the least (Fig. 2(a)).

The Junggar Basin was a compressional basin in the Triassic and its development was related to the movement of the Zaire Hill orogenic wedge. The controlling process of the distribution of fan bodies by the Ke-Bai fault gradually weakened and disappeared and the fans withdrew back to the margin of the basin. The lower Triassic Baikouquan 
Formation was eroded on the hanging wall. The area and scale of alluvial fans on the foot wall is large and the rock mainly consists of pebbled sandstone in the Karamay member. With an abundant source of sediment, the area of alluvial fan deposited in the Baikouquan member is the largest and the rock consists mainly of sandy conglomerate, secondly pebbled sandstone and sandstone. The middlelate Triassic alluvial fan bodies deposited in the Karamay member withdrew to the foot of the Zaire Hill. Besides, both on the hanging wall and the foot wall, braided river delta deposition developed widely. The rock grain size became smaller towards the basin centre (Fig. 2(b)). In the Baikouquan area, with steady sediment sources, the earlymiddle Triassic alluvial fan bodies developed successively and were characterized by large sets of sandy conglomerate. The late Triassic alluvial fan bodies were not developed in the whole study area. The pebbled sandstone deposition of braided river facies developed on the hanging wall, and the sandstone deposition of braided river delta facies developed on the foot wall.

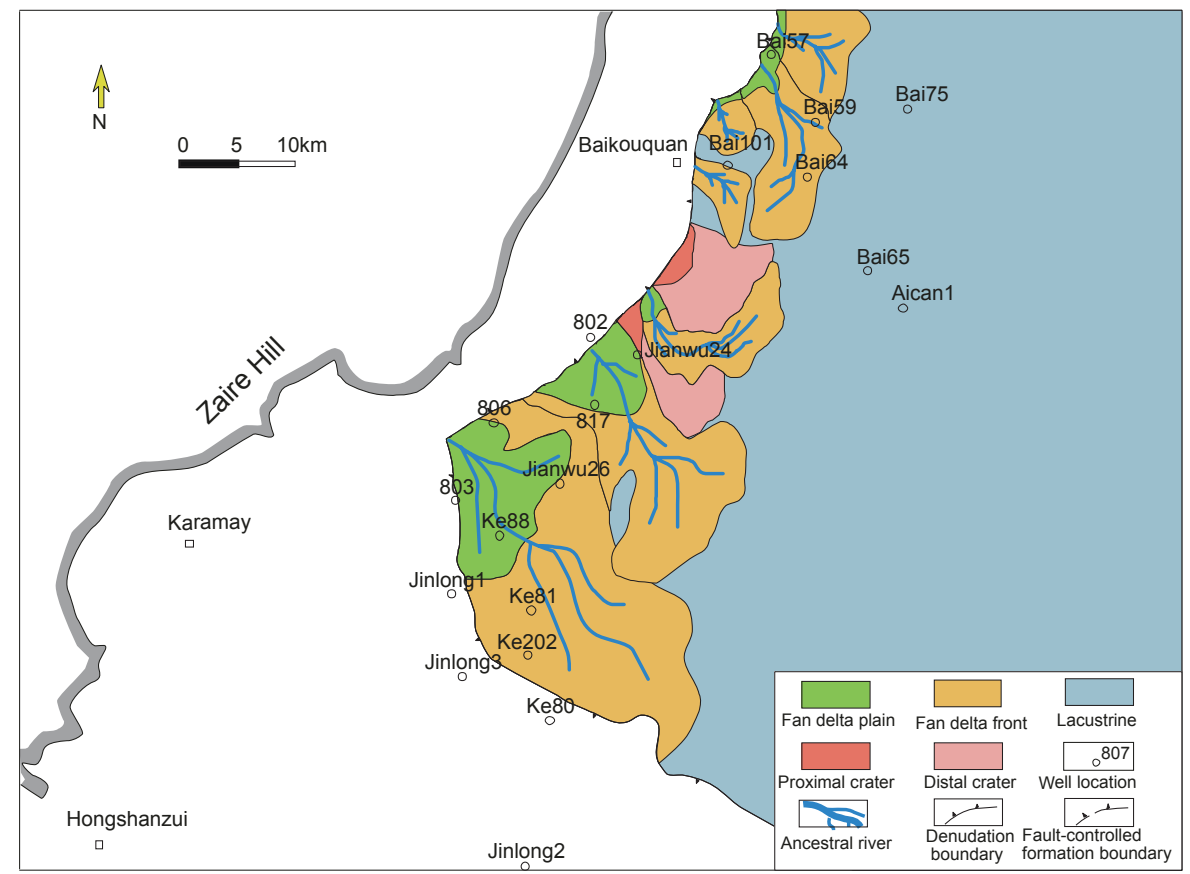

(a) Distribution of depositional systems of the Fengcheng Formation in the lower Permian

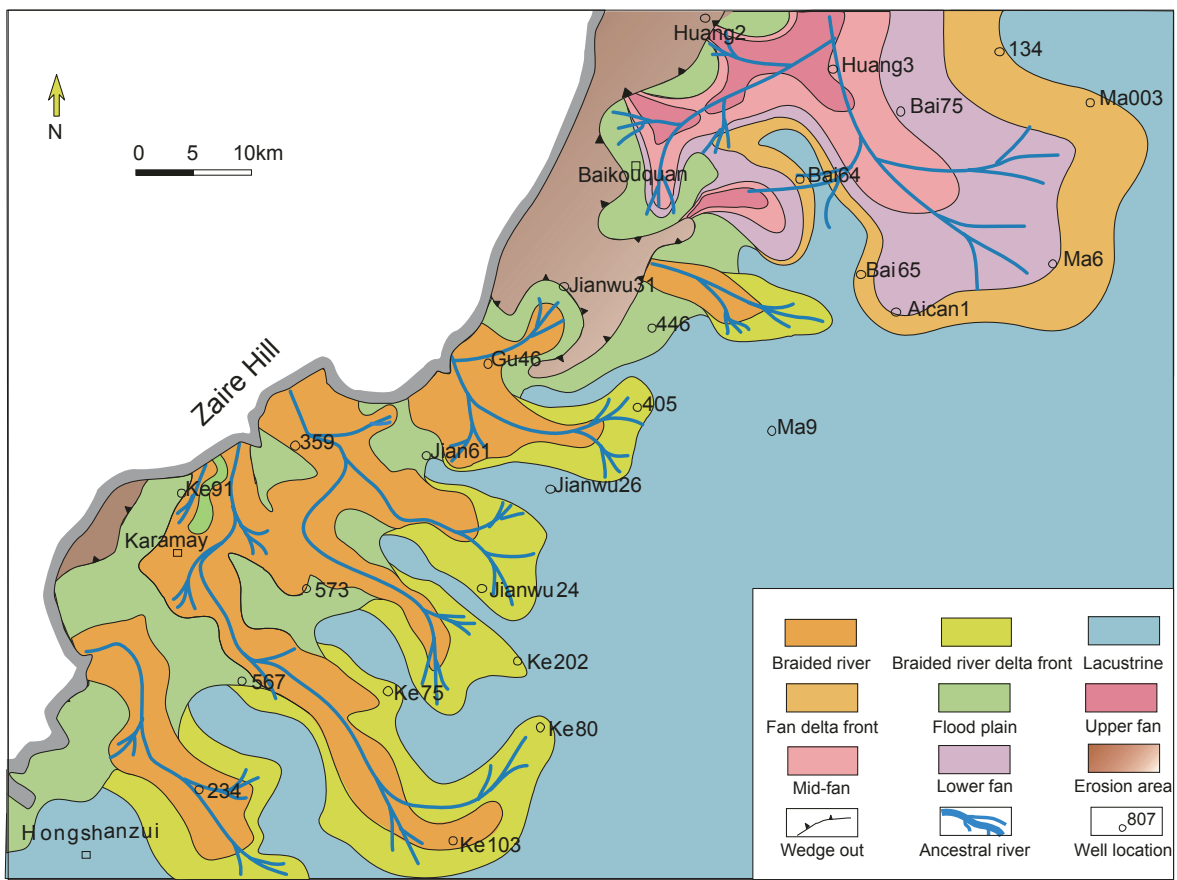

(b) Distribution of depositional systems of the lower Karamay Formation in the middle Triassic 


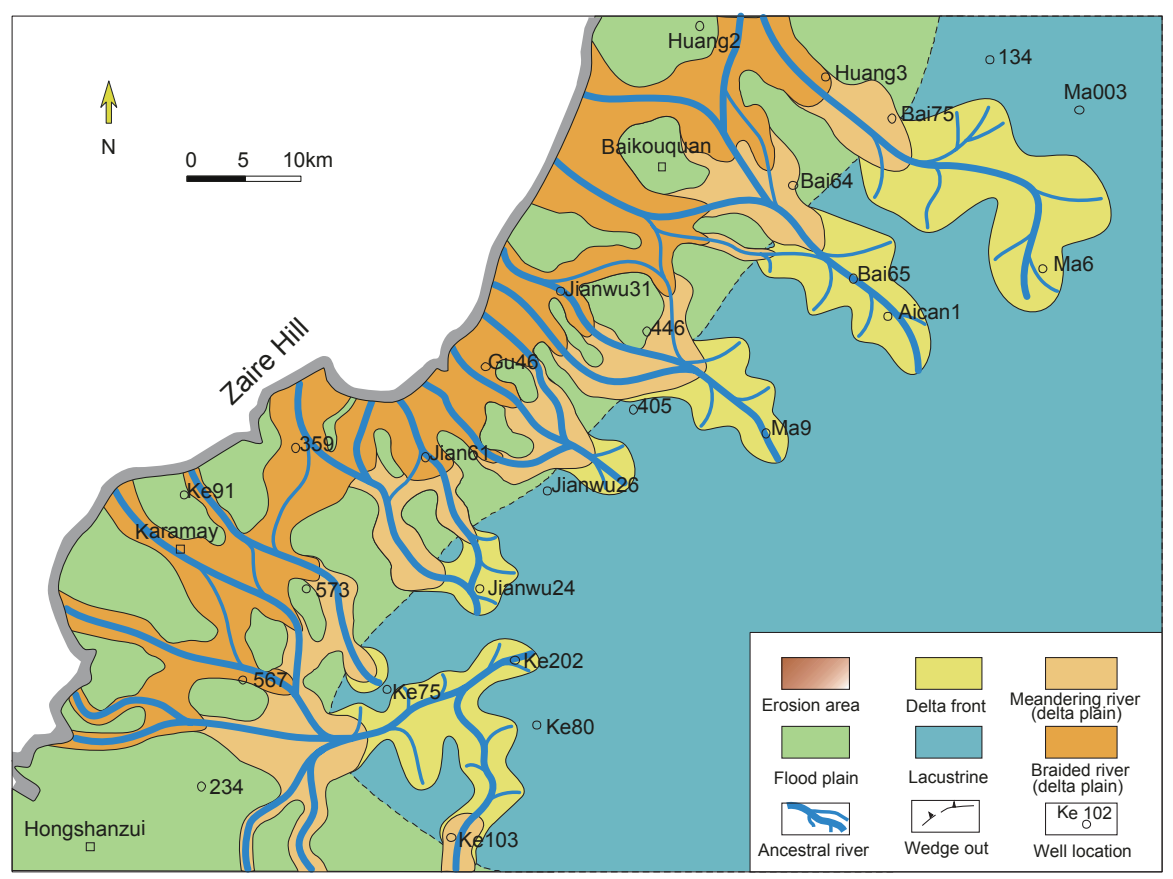

(c) Distribution of depositional systems of the lower Badaowan Formation and upper Sangonghe Formation in the lower Jurassic

Fig. 2 Sedimentary facies maps of the key layers in Permian-Jurassic in the Ke-Bai area, Junggar Basin

The development of alluvial fans in the Jurassic was similar to that in the Triassic. It was controlled by the KeBai fault in the early stage, while the control disappeared in the late stage, and the fan bodies withdrew to the margin of the basin. In the early Jurassic Badaowan Formation, the fault was relatively active, and the successional Baikouquan alluvial fans deposited on the foot wall along the fault were on a large scale. The rock mainly consisted of sandy conglomerate and pebbled sandstone. The lower Badaowan Formation and the Toutunhe Formation in the middle Jurassic were eroded on the hanging wall. In other stages, the fault activity was weak and did not affect the development of alluvial fans. Braided river deposits containing pebbled sandstone and sandstone developed on the hanging wall and braided river delta deposits containing sandstone developed on the foot wall (Fig. 2(c)).

Generally, the scale of fan bodies decreased from Permian to Jurassic in the Ke-Bai area, and the grain size of rock also decreased, which reflect the weakening of fracturing. The development characteristics of fan bodies between the Karamay member and Baikouquan member are different, which indicate that the fracturing intensity in different areas varies. Based on the relationship between Mesozoic depositional systems and the Zaire Hill, we think that the boundary fault and border facies or basin boundary are missing. Therefore, the Mesozoic depositional scope is larger than present, and the accurate position of the sedimentary boundary needs to be studied further.

\section{Differences of reservoir properties between the hanging wall and the foot wall}

The thrusting of the Ke-Bai fault leads to different burial history, diagenetic evolution, porosity evolution, and reservoir quality between the hanging wall and the foot wall. Based on the burial history, we discussed the rule of vertical porosity evolution and its relationship with thrusting through comparison and analysis of the differences of PermianJurassic reservoir quality between the hanging wall and the foot wall.

\subsection{Basin subsidence and burial history}

The basin subsidence in the Ke-Bai area can be divided into three stages since the Permian. The first is the earlymiddle Permian with a steep subsidence curve. In the late middle Permian, an event occurred which led to uplifting and erosion of strata. The second is from the late Permian to the middle Jurassic, and the subsidence curve becomes gentle. The last is from the late Jurassic to the early Cretaceous, and the subsidence curve becomes steep again (with smaller slope than the first stage). Consequently, the characteristics of the Permian-Jurassic burial history can be summarized as fast subsidence in the early stage, slow subsidence in the middle stage, and fast subsidence in the late stage. In space, the farther away from the Ke-Bai fault, the smaller the subsidence rate (Fig. 3, line 2 and 3), especially during the first and last stages, which reflects the control of the overthrust fault on sedimentation. Compared with the hanging wall, the foot wall has larger subsidence rate in the same sedimentary period. 


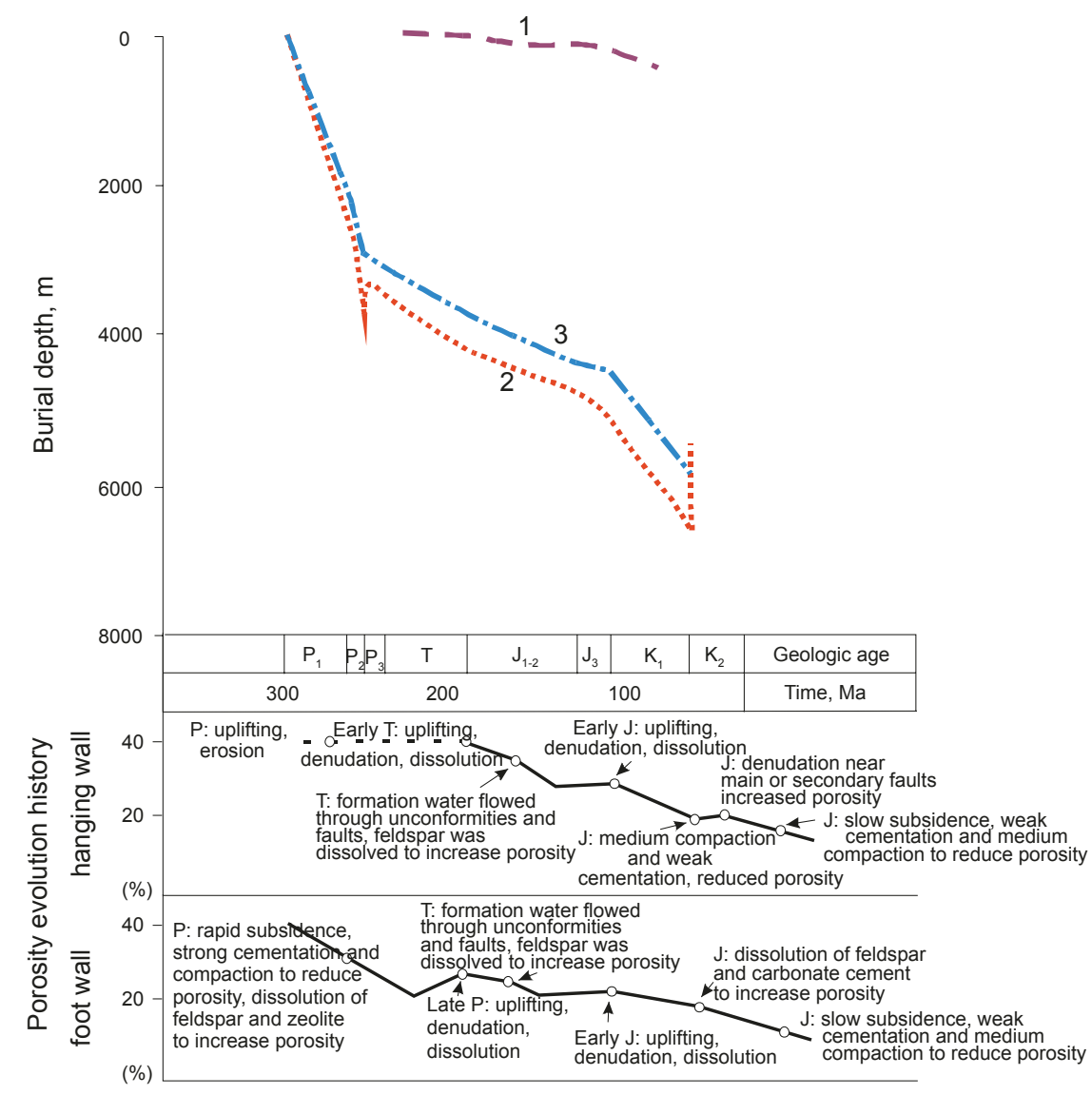

Line 1: hanging wall (Well Gu49); Line 2: proximal foot wall; Line 3: distal foot wall

Note: Line 2 and 3 are based on the burial depth of seismic section KB200601, see BB' in Fig. 1 for the section location

Fig. 3 Burial history and porosity evolution of the hanging wall and the foot wall in the Ke-Bai overthrust zone

\subsection{Reservoir pore evolution on the hanging wall}

The burial depth of strata on the hanging wall is shallow, generally less than $2,300 \mathrm{~m}$. The Permian, lower Triassic and lower Jurassic strata were eroded in different degrees due to the effect of thrusting, and other strata slowly and steadily subsided (Fig. 3, line 1). Because of shallow burial depth, the reservoir compaction is weak and primary pores are preserved well. Moreover, because of the secondary fractures on the hanging wall, it was easy for acid fluid to enter the strata through faults and unconformities, and dissolution improved the reservoir quality. The porosity of the reservoir on the hanging wall is generally $10 \%-25 \%$.

The burial depth of the Triassic reservoir on the hanging wall is less than $2,200 \mathrm{~m}$, and the reservoir is in the stage B of the early diagenetic phase to stage A of the middle diagenetic phase. The primary pores are well preserved, and secondary pores are mainly enhanced intergranular dissolution pores (Fig. 4(c)). There are two unconformities caused by uplifting and erosion both on the top and bottom of Triassic. During dissolution, the strata underwent eluviation with atmospheric water which entered the strata along faults or unconformities and mixed with formation water to form acid water (Qiu et al, 1994; Zhang et al, 2007; Zhu et al, 2004). The content of dissolution pores increases with deepening burial depth, and the proportion of primary pores decreases gradually.
Above $500 \mathrm{~m}$ on the hanging wall, primary pores are the main porosity type. The average porosity is about $22 \%$ and the permeability is $639 \times 10^{-3} \mu \mathrm{m}^{2}$. At depths of $500-800 \mathrm{~m}$, the proportion of secondary pores increases, forming a mixed pore type with $30 \%-50 \%$ dissolution pores. Below $800 \mathrm{~m}$, the dissolution became intense, and the proportion of secondary pores is greater than $50 \%$. The pore type is a combination of intergranular and intragranular dissolution pores, showing medium dissolution intensity. There are three secondary pore belts on the hanging wall at depths of 500-2,500 $\mathrm{m}$ and these are at $900-1,100 \mathrm{~m}, 1,200-1,350 \mathrm{~m}$, and $1,800-2,150 \mathrm{~m}$. The average porosities are $16 \%, 14.4 \%$, and $12.1 \%$ respectively, which are $3 \%-10 \%$ higher than that of normal compaction.

The burial depth of Jurassic strata with weak compaction on the hanging wall is about $0-1,900 \mathrm{~m}$, and the primary pores are well preserved (Fig. 4(e)). The characteristics of diagenetic facies are weak compaction, weak cementation, and weak dissolution (Zhu et al, 2008). In the early period of the early Jurassic and the late period of the middle Jurassic, the Ke-Bai overthrust fault acted intensely, and the strata on the hanging wall were eroded. Affected by the connection of faults and unconformities, acidic fluid easily entered the reservoir and dissolution generally developed. However, the dissolution intensity is quite weak and the proportion of secondary pores is much smaller than primary pores. With increasing burial depth, primary pores are partly damaged 
and secondary pores become more significant. The reservoir characterized by primary pores is above $1,000 \mathrm{~m}$ and the pore type is mainly residual primary pores. The average porosity is about $19.2 \%$ and the permeability is $479 \times 10^{-3}$ $\mu \mathrm{m}^{2}$. Below $1,000 \mathrm{~m}$, the proportion of secondary pores increases and the reservoir pores consist of secondary pores and primary pores. In the southeast ninth area (near the South Baijiantan Fault, see Fig. 1) and Baikouquan north area, the proportion of secondary pores is over $50 \%$, showing medium dissolution intensity. In the depth of 1,000-1,900 m, there are two secondary pore belts: $1,060-1,120 \mathrm{~m}$ and 1,550-1,630 m. The average porosities are $17 \%$ and $16.3 \%$ respectively. The development of secondary pores has a positive correlation with the content of carbonate (Zhu et al, 2008).

\subsection{Reservoir pore evolution on the foot wall}

The strata on the foot wall are completely developed and deeply buried. Influenced by three stages of subsidence, the porosity decreases with increasing depth. In the frontal zone, the porosity of Triassic-Jurassic reservoir is about 10\%-20\%, and that of Permian reservoir is about 5\%-15\%. The reservoir properties in the Baikouquan area are slightly better than those in the fifth and eighth areas because of shallow burial depth, coarse grain size and strong anti-compaction ability. In the slope zone, with increasing burial depth, the compaction strengthened and the primary pores were almost lost. In addition, less effect of fault activity, fine grain size, and high shale content are not favorable for the flow of acidic fluid and development of dissolution (Jiang et al, 2006). Therefore, the reservoir quality in the slope zone is worse than that in the frontal zone of foot wall and hanging wall.

The Permian clastic reservoir was mainly formed by alluvial fan and fan delta depositional systems in the frontal zone and is in the stage A of the middle diagenetic phase. Secondary porosity is the main pore type. The contact relation of clastic grains is mostly line contact, occasionally concave convex contact. The characteristics of diagenetic facies are relatively strong compaction, medium-strong cementation and weak dissolution. The reservoir burial depth in the frontal zone of the fifth and eighth areas (beside Karamay Fault, see Fig. 1) is 1,500-4,500 $\mathrm{m}$, and the porosity is about $5 \%$ $15 \%$. As a whole it is a low porosity and low permeability Permian reservoir. The dissolution in the frontal zone is quite strong because of the effect of the Ke-Bai fault. In some areas, the dissolution intensity is medium, and it is common to find dissolution of zeolite and feldspar (Fig. 4(a) and (b)). Secondary pores are mainly intergranular, intragranular, intracrystal and intercrystal dissolved pores and microcracks. The burial depth in the Baikouquan area is shallower than that in the fifth and eighth areas and the porosity is about $10 \%$ $22 \%$. The primary pores are mainly distributed at depths of $1,000-1,450 \mathrm{~m}$ and the mixed pores are 1,450-1,600 m deep. Below $1,600 \mathrm{~m}$, the porosity type is secondary pore and the development of secondary pores is weaker than that in the fifth and eighth areas.

The Triassic strata on the foot wall are completely developed and the burial depth is in the range of 1,200-1,300 $\mathrm{m}$. The reservoir is in the stage A of the middle diagenetic phase. Due to strong compaction, primary pores are gradually missing and the reservoir is characterized by secondary pores. The dissolution of feldspar is common (Fig. 4(d)). At depths of 1,200-3,600 $\mathrm{m}$ on the foot wall, three secondary pore belts are developed: $1,500-1,800 \mathrm{~m}, 1,950-2,500 \mathrm{~m}$, and 3,050$3,500 \mathrm{~m}$. The average porosities are $13.8 \%, 11.5 \%$, and $9.2 \%$ respectively, which are $5 \%-10 \%$ higher than that of normal compaction. The development of secondary pores does not have obvious correlation with the content of carbonate, but it has positive correlation with the content of kaolinite. It shows that the dissolved matter on the foot wall was not carbonate cement, but feldspar.

Compared with the Jurassic reservoir on the hanging wall, the reservoir characterized by primary pores on the foot wall is locally distributed. The burial depth is less than $1,000 \mathrm{~m}$ and the average porosity is about $17 \%$. In the depth of 1,000 $1,450 \mathrm{~m}$, the pore type is mainly mixed pores and the average porosity is about $16.8 \%$. Below $1,600 \mathrm{~m}$, the reservoir is characterized by secondary porosity, especially near the frontal zone of the fault (Fig. 4(f)).

\section{Formation mechanism and controlling factors of reservoir differences}

The thrusting of the Ke-Bai fault resulted in differences of reservoir quality between the hanging wall and the foot wall. In detail, different burial histories, burial depths, depositional systems, and diagenetic evolution have different effects on the reservoir quality of the hanging wall and the foot wall. The Ke-Bai overthrust fault is a compression-nappe fracture, and is characterized by overriding and contemporaneous faulting. Influenced by the fault activity, the strata on the hanging wall were compressed and uplifted, and were eroded to different degrees. Because of shallow burial depth and relatively simple diagenesis, the reservoir properties were little affected and a large number of primary pores were preserved (Fig. 4(e)). The proportion of dissolution pores is quite small, but increases with increasing depth. On the foot wall, the strata steadily subsided (except a large-scale uplift in late Permian, Fig. 3). The reservoir is deeply buried, which leads to strong compaction and cementation. Dissolution is well developed in the frontal zone and near sub-faults (Fig. 4(a), (b), (c), (d), and (f)). Less effect of fault activity and high shale content are not favorable for the flow of formation water and development of dissolution. Therefore the reservoir quality in the slope zone is worse than that in the frontal zone of foot wall and hanging wall. Comprehensive analysis shows that the reservoir burial history (fracture evolution history) controls facies combination, reservoir burial depth, and the formation of secondary pores in the study area. Depositional systems affected by the Ke-Bai fault have an impact on the reservoir grain size, compositional and textural maturity, and control the development of primary pores.

\subsection{Effect of burial history on reservoir quality}

The Permian strata were not developed on the hanging wall of the nappe due to the effect of Hercynian movement. Since the Triassic, affected by thrusting, the strata were occasionally uplifted during the process of steady subsidence. The strata 

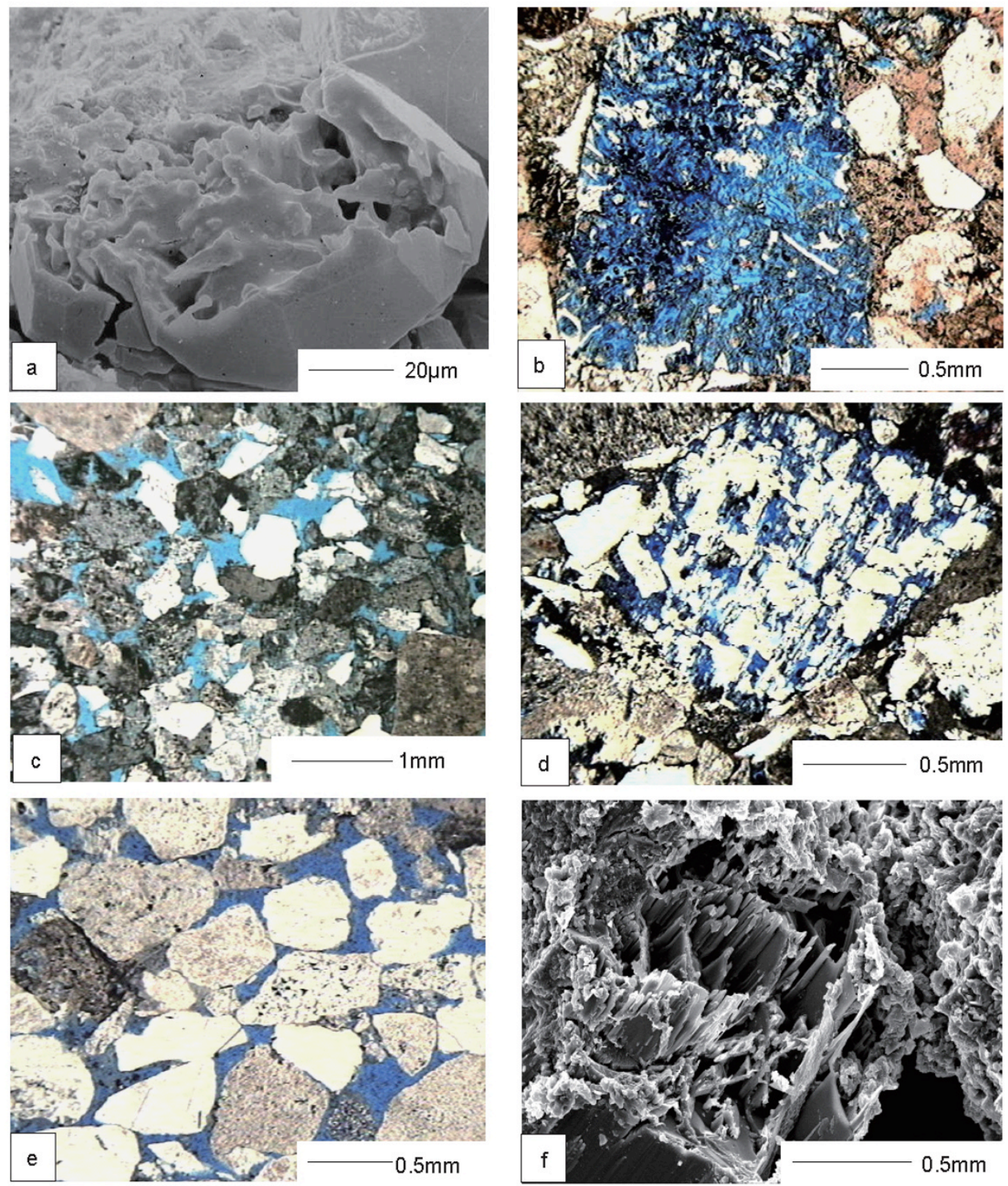

(a) SEM image: Dissolved analcite, sandstone, Well Jianwu-44, Permian on the foot wall, $22,877.74 \mathrm{~m}, \varphi=15.18 \%$

(b) Intragranular dissolution pore, sandy conglomerate, Well B1803, Permian on the foot wall, 1,702.12 $\mathrm{m}, \varphi=5.1 \%$

(c) Dissolved pores of calcite cement, pebbled sandstone, Well Ke-91, Triassic on the hanging wall, $72.04 \mathrm{~m}, \varphi=21.6 \%$

(d) Intragranular dissolution pore, sandy conglomerate, Well Ke-303, Triassic on the foot wall, 3,532.99 $\mathrm{m}, \varphi=12.2 \%$

(e) Residual primary pore, medium sandstone, Well Ke-901, Jurassic on the hanging wall, $819 \mathrm{~m}, \varphi=22.4 \%$

(f) SEM image: Dissolution of feldspar, medium sandstone, Well Ke-93, Jurassic on the foot wall, $465.2 \mathrm{~m}, \varphi=33.4 \%$

Fig. 4 Microscopic photographs of Permian-Jurassic reservoir differences between the hanging wall and the foot wall

were eroded with thickness less than $2,300 \mathrm{~m}$. Shallow burial depth, weak compaction, and weak cementation enabled large numbers of primary pores to be preserved. The strata were eroded and underwent eluviation from atmospheric water. The connection of unconformities and faults is favorable for the formation of secondary pores. The porosity is generally larger than $16 \%$ on the hanging wall. In the middle-late Permian, the foot wall uplifted significantly, which eroded the strata in the frontal zone of the Karamay fault to different degrees. The later dissolution improved the reservoir quality. Because the Permian strata were deeply buried (commonly deeper than $2,000 \mathrm{~m}$ ) with strong compaction and cementation, the primary pore structure suffered severe damage. Thus, the reservoir property was poor and the porosity was generally smaller than $10 \%$. The favorable reservoir on the foot wall is generally developed near the (main or secondary) faults or in the channel sand bodies, which is because there are large numbers of secondary pores in the areas. The dissolution of zeolite is important for the Permian reservoir (Fig. 4(a)) and the distribution of zeolite is controlled by the content of tuff debris.

\subsection{Control of depositional systems on reservoir property}

Grain size and compositional and textural maturity are important factors in controlling reservoir quality in the study 
area. The reservoir on the hanging wall is near the sediment source with lower compositional maturity and shallow burial depth. Because of coarse grain size, the compaction is weak and a large number of primary pores are preserved. Influenced by braided channel scouring in the middle of the fan bodies, the textural maturity of the reservoir is medium and the matrix content is low, which are favorable for the flow of acidic fluid. Dissolution is widely developed and the intensity is medium to weak. The reservoir on the foot wall is far away from the source of the sediments and the compositional maturity is higher than that on the hanging wall. The lithology is mainly lithic sandstone. With deep burial depth and fine grain size, the space of primary pores has suffered severe compaction damage. In spite of better sorting and psephicity than those on the hanging wall, secondary pores are not developed on the foot wall owing to the lack of sub-fault activity and high shale content. The content of secondary pores in the frontal zone is slightly higher than that in the slope zone.

During the Permian, early Triassic, the early period of the early Jurassic, and the late period of the middle Jurassic, the activity of overthrust faulting was intense and the strata on the hanging wall were compressed and uplifted. The extent of uplifting is controlled by the segmental activity of the overthrust fault, which is different between the Baikouquan fault and the Karamay fault. For the Baikouquan fault, with strong activity of overthrust fault and abundant provenance, the inherited alluvial fan bodies extended from the hanging wall to the slope zone of the foot wall. The shallow burial depth and favorable deposition conditions contribute to better reservoir properties in the Baikouquan fault segment than those in the Karamay fault segment.

\section{Conclusions}

1) The Ke-Bai overthrust fault formed in the late Carboniferous-early Permian had a long active history, and was characterized by thrusting and contemporaneous faults. It controlled the time-space distribution of Permian-Jurassic depositional systems.

2) The thrusting of the Ke-Bai fault resulted in different reservoir qualities between the hanging wall and the foot wall of the fault zone. Different characteristics of burial history had different effects on compaction, cementation, and dissolution, as well as the vertical distribution of porosity. Favorable reservoirs on the foot wall were generally developed near faults or in the channel sand bodies, which were usually dissolution development areas.

3) Sedimentation controlled by the overthrust fault and burial history are direct factors resulting in different reservoir qualities between the hanging wall and the foot wall.

\section{Acknowledgements}

This work is financially supported by the National Program for Fundamental Research and Development (973 Program 2006CB202306). We are very grateful to Zhang Yueqian and Chen Zhiwen from Xinjiang Oilfield Company, CNPC for their careful direction and assistance. We also give thanks to the Research Institute of Petroleum Exploration and Development, PetroChina.

\section{References}

Bloch S, McGowen J H, Duncan J R, et al. Porosity prediction, prior to drilling, in sandstones of the Kekiktuk Formation (Mississippian), North Slope of Alaska. AAPG Bulletin. 1990. 74(9): 1371-1385

Harris N B. Reservoir geology of Fangst Group (Middle Jurassic), Heidrun Field, offshore mid-Norway. AAPG Bulletin. 1989. 73(11): 1415-1435

He D F, Yin C, Du S K, et al. Characteristics of structural segmentation of foreland thrust belts - A case study of the fault belts in the northwestern margin of Junggar Basin. Earth Science Frontiers. 2004. 11(3): 91-101 (in Chinese)

Jiang Z X, Chen D X, Pang X Q, et al. Control of formation of lithological reservoirs by surrounding mudstone. Petroleum Science. 2006. 3(2): 1-6

Kuang J, Zhang Y Q and Hou L H. Exploratory targets of KaramayBaikouquan buried structural belt in northwestern margin of Junggar Basin. Xinjiang Petroleum Geology. 2008. 29(4): 431-434 (in Chinese)

Lei Z Y, Bian D Z, Du S K, et al. Characteristics of fan forming and oilgas distribution in north-west margin of Junggar Basin. Acta Petrolei Sinica. 2005a. 26(1): 8-12 (in Chinese)

Lei Z Y, Lu B, Wei Y J, et al. Tectonic evolution and development and distribution of fans on northwestern edge of Junggar Basin. Oil \& Gas Geology. 2005b. 26(1): 86-91 (in Chinese)

Lu B, Zhang J, Li T, et al. Analysis of tectonic framework in Junggar Basin. Xinjiang Petroleum Geology. 2008. 29(3): 283-289 (in Chinese)

Payne J H. Diagenetic variations in Permo-Triassic Ivishak sandstone in Prudhoe Bay Field and central-northeastern National Petroleum Reserve in Alaska (NPRA). In: Tailleur I and Weimer P, eds., Alaska North Slope Geology: SEPM Pacific Section and Alaska Geological Society. 1987: 77-83

Qiu D Z, Zhang J Q, Wang X L, et al. Deposition and Diagenesis of Triassic-Jurassic Reservoir in Northwestern Margin, Junggar Basin. Chengdu: Chengdu University of Science and Technology Press. 1994 (in Chinese)

Shou J F, Zhu G H and Zhang H L. Lateral structure compression and its influence on sandstone diagenesis - A case study from the Tarim Basin. Acta Sedimentologica Sinica. 2003. 21(1): 90-95 (in Chinese)

Tan K J, Zhang F, Wu X Z, et al. Basin-range coupling and hydrocarbon accumulation at the northwestern margin of the Junggar Basin. Natural Gas Industry. 2008. 28(5): 10-13 (in Chinese)

Zhang J L, Jia Y and Du G L. Diagenesis and its effect on reservoir quality of Silurian sandstones, Tabei area, Tarim Basin, China. Petroleum Science. 2007. 4(3): 1-13

Zhu S F, Zhu X M, Liu Z Y, et al. Jurassic diagenesis and its control on reservoir quality in Ke-Bai area, northwestern margin of Junggar Basin. Geological Journal of China Universities. 2008. 14(2): 172180 (in Chinese)

Zhu X M, Zhong D K, Zhang Q, et al. Sandstone diagenesis and porosity evolution of Paleogene in Huimin Depression. Petroleum Science. 2004. 1(3): 23-29

Zou C N, Hou L H, Kuang L C, et al. Genetic mechanism of diagenesisreservoir facies of the fan-controlled Permo-Triassic in the western marginal area, Junggar Basin. Chinese Journal of Geology. 2007. 42(3): 587-601 (in Chinese) 